Acta Theriologica $36(1-2): 193$ - 199, 1991.

PL ISSN $0001-7051$

\title{
B chromosome system in populations of Oryzomys flavescens (Rodentia, Cricetidae) from southern Brazil
}

\author{
Ives J. SBALQUEIRO*, Margarete S. MATTEVI, Luiz F. B. OLIVEIRA \\ and Maria J. V. SOLANO
}

\begin{abstract}
Sbalqueiro I. J., Mattevi M. S., Oliveira L. F. B. and Solano M. J. V. 1991. B chromosome system in populations of Oryzomys flavescens (Rodentia, Cricetidae) from southern Brazil. Acta theriol. 36: $193-199$.

Chromosome studies on 49 specimens collected from 11 Brazilian populations of the rodent species Oryzomys flavescens (Waterhouse, 1837) disclosed $2 n=64$ in 25 individuals, $2 n=65$ in $9,2 n=66$ in 12 , and $2 n=64 / 65$ mosaics in 3 . This chromosome variation was due to the occurrence of one or two extra small heterochromatic acrocentrics, interpreted as B chromosomes. Comparisons made between our data and those previously reported for $O$. flavescens from Uruguay and Argentina, O. fornesi from Paraguay, and Oryzomys sp. from São Paulo, Brazil, revealed that these taxa share similar karyotypes, suggesting they belong to a single cytotaxonomic group.

Departamento de Genética, Universidade Federal do Rio Grande do Sul, C. P. 15053, 91501, Porto Alegre, RS, Brazil. Reprint requests should be addressed to MSM

Key words: B chromosome variation, Oryzomys flavescens, Brazil
\end{abstract}

\section{Introduction}

Oryzomys Baird, 1858 is a complex neotropical cricetid genus distributed from the east of the United States to the Straits of Magellan. Its species number ranges, according to authority, from approximately 45 (Reig 1986) to over 100 (Haiduk et al. 1979), this discrepancy partly reflecting the disagreement over whether certain taxa should be included as subgenera or distinct genera. Among the subgenera proposed, Olygoryzomys comprises 15 nominal species (Carleton and Musser 1989), their members being an important component of neotropical communities of small mammal. Oryzomys flavescens (Waterhouse 1837) is a species belonging to this subgenus which is characterized by small body size (total length $\mathrm{ca} .20 \mathrm{~cm}$ ), small ears and long tail (about 60 percent of total length) and feet. Dorsally it is brown-orange and ventrally yellow-gray in colour (Langguth 1963, Fornes and Massoia 1965). It occurs in Brazil, Uruguay and Argentina; Minas Gerais (eastern Brazil) being the most northern locality recorded and Chubut Province, Argentina, the most southern (Carleton and Musser 1989).

Previously, the karyotype of $O$. flavescens has been investigated in Uruguay and Argentina, where diploid numbers of 64 and 66 were found (Brum-Zorrilla et al. 1988). In this paper we will describe the karyotypic variation observed in specimens collected in 11 different sites from Brazil, which show that $O$.flavescens has a system of accessory chromosomes which

*Present address: Departamento de Genética, Universidade Federal do Paraná, Curitiba, PR, Brazil 
is apparently shared by Oryzomys sp. and $O$. fornesi, two other previously described forms of Olygoryzomys (Yonenaga et al. 1976, Kasahara 1978, Myers and Carleton 1981).

\section{Material and methods}

The sample comprised 29 males and 20 females caught in 11 localities from southern Brazil. Their geographical location is given in Fig. 1 (localities $4-14$ ). In this figure are also the collecting sites given for two other Olygoryzomys showing similar or identical karyotypes as $O$. flavescens. Skins and skulls of the individuals studied are deposited in the Mammal Collection of our Department.

The technique of Ford and Hamerton (1956), and Ford and Evans (1969) were used to obtain bone marrow and testis cells, respectively. G-, C-, and NOR-banding were performed by the Seabright (1971), Sumner (1972), and Howell and Black (1980) methods.

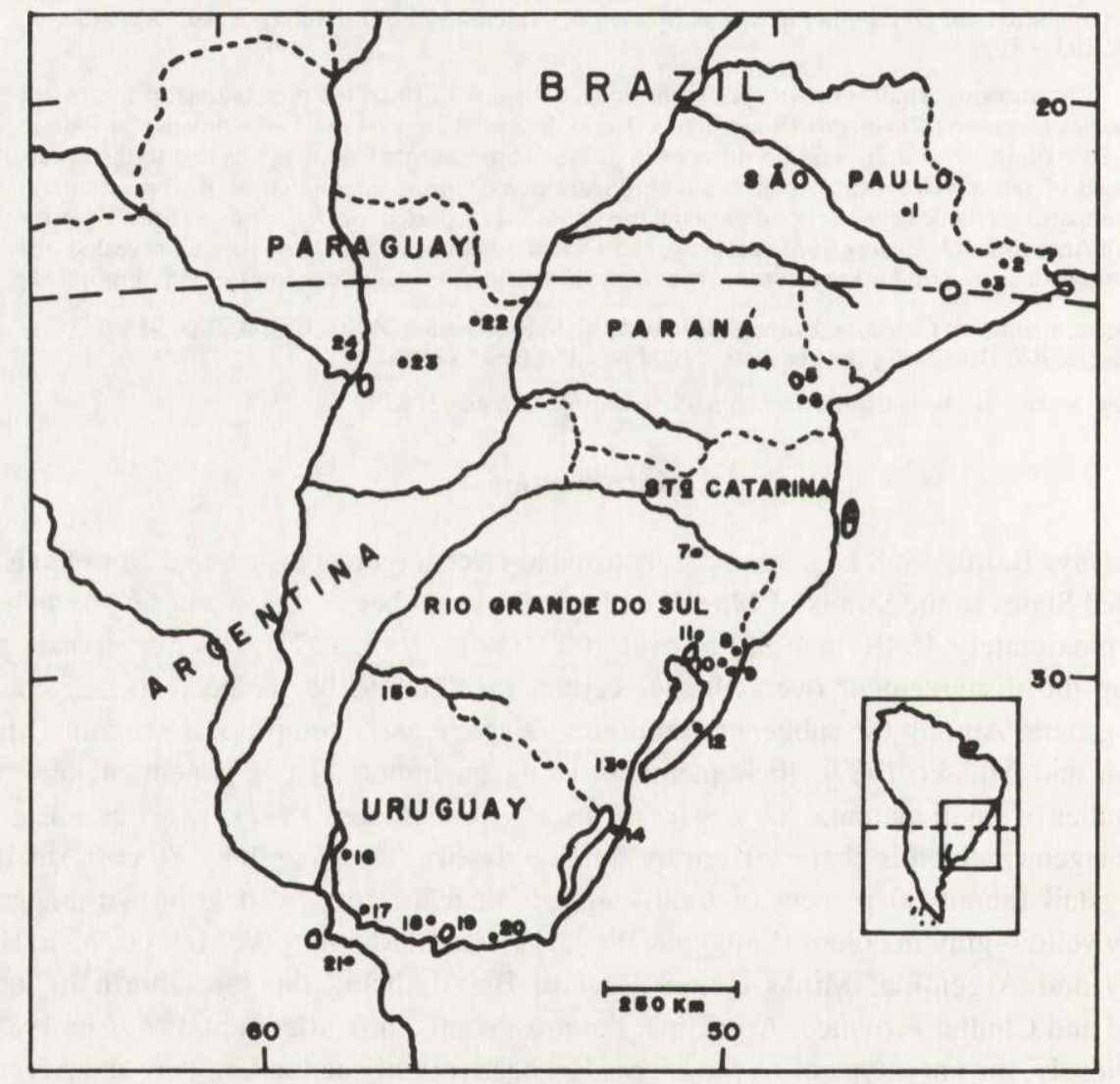

Fig. 1. Collecting sites of Olygoryzomys taxa with diploid numbers of 64 to 66. Brazil: 1. Americana; 2. Caçapava; 3. Guararema; 4. Ponta Grossa; 5. Curitiba; 6. Piraquara; 7. Esmeralda; 8. Torres; 9. Tramandai; 10. Osório; 11 . Sapiranga; 12. Mostardas; 13. Pelotas; 14. Taim. Uruguay: 15. Artigas; 16. Fray Bentos; 17. Colonia; 18. Canelones; 19. Montevideo; 20. Maldonado. Argentina; 21. La Plata. Paraguay; 22. Curuguaty; 23. Carayaó; 24. La Golondrina. Localities 1 to 3 according to Yonenaga et al. (1976) and Kasahara (1978); 4 to 14, this work; 15 to 21, Brum-Zorrilla et al. (1988); 22 to 24, Myers and Carleton (1981). 


\section{Results}

Twenty-five specimens from ten localities (Table 1) showed the basic karyotype of the species $(2 n=64, F N=66)$ which consists of 58 acrocentrics of various sizes and four small biarmed chromosomes. Nine individuals had an extra tiny acrocentric (formula: $2 n=65$, $\mathrm{FN}=67$ ), which occurred in 2 copies in the 12 rats with $2 \mathrm{n}=66, \mathrm{FN}=68$. In three animals a $2 n=64 / 65$ mosaicism was observed with at least $30 \%$ of the cells being $2 n=64$ in 18 cells analyzed per animal.

Table 1. Characteristics of the karyotype of $O$. flavescens.

\begin{tabular}{|c|c|c|c|c|c|c|c|}
\hline \multirow{2}{*}{ Localities* } & \multicolumn{3}{|c|}{ Number studied } & \multicolumn{2}{|c|}{ Chromosome numbers** } & \multicolumn{2}{|c|}{ Autosome morphology } \\
\hline & Males & Females & Total & $2 n$ & $\mathrm{NF}_{\mathrm{a}}$ & M-SM & A \\
\hline $4,5,6,7,8,9,10,11,12,14$ & 16 & 9 & 25 & 64 & 66 & 4 & 58 \\
\hline $4,6,7,14$ & 6 & 3 & 9 & 65 & 67 & 4 & 59 \\
\hline 4,9 & 2 & 1 & 3 & $64 / 65$ & $66 / 67$ & 4 & $58 / 59$ \\
\hline $4,6,7,8,13,14$ & 5 & 7 & 12 & 66 & 68 & 4 & 60 \\
\hline
\end{tabular}

* Numbers correspond to those of Fig. 1.

** $\mathrm{NF}_{\mathrm{a}}=$ autosomal arms; $\mathrm{M}-\mathrm{MS}=$ metacentric-submetacentric; $\mathrm{A}=$ acrocentric.

Fig. 2 shows karyotypes of $O$. flavescens. With conventional staining (Fig. 2A) only chromosome pair number 1 , the two small bairmed pairs, the sex chromosomes and the extra elements of karyotypes with $2 n=65$ and 66 are identifiable. The X chromosome is a median submetacentric (with a size which is intermediate between autosome pairs number 1 and 2) showing a variable centromeric index. The $\mathrm{Y}$ chromosome is also submetacentric (15 specimens) or metacentric (10 animals) but occurred also in acrocentric (two individuals of locality 6, Fig. 1) and subtelocentric (one male, locality 14) forms. With G-banding (Fig. 2B) it was possible to identify all the autosome pairs; those of smaller size, however, have very similar patterns. Constitutive heterochromatin occurred as conspicuous pericentromeric blocks present on all autosome pairs (Fig. 2C). The B chromosomes are entirely C-positive, but the staining is less intense. The $\mathrm{X}$ chromosome has a heterochromatic short arm, which is responsible for the observed variable centromeric indexes. The $\mathrm{Y}$ is entirely hetrochromatic. In Piraquara (locality 6, Fig. 1) the morphology and C-band patterns of the Y chromosome were variable. In four males it was metacentric and in two it was acrocentric. The metacentric $\mathrm{Y}$ chromosome was C-positive over half their short arms, while the acrocentrics were entirely heterochromatic.

Fig. 3 shows the NOR-bands. They occurred on the short arms of the small acrocentrics, with a mean of $4.3 \pm 0.7 \mathrm{ER}$ per cell $(\mathrm{N}=50)$, and ranging from two to eight.

Additional chromosome polymorphisms were observed. Five specimens (from Taim, Pelotas, and Esmeralda, see Fig. 1) showed enlarged short arms on autosome pair number 1 due to variation in quantity of constitutive heterochromatin (Fig. 4A). The same kind of 


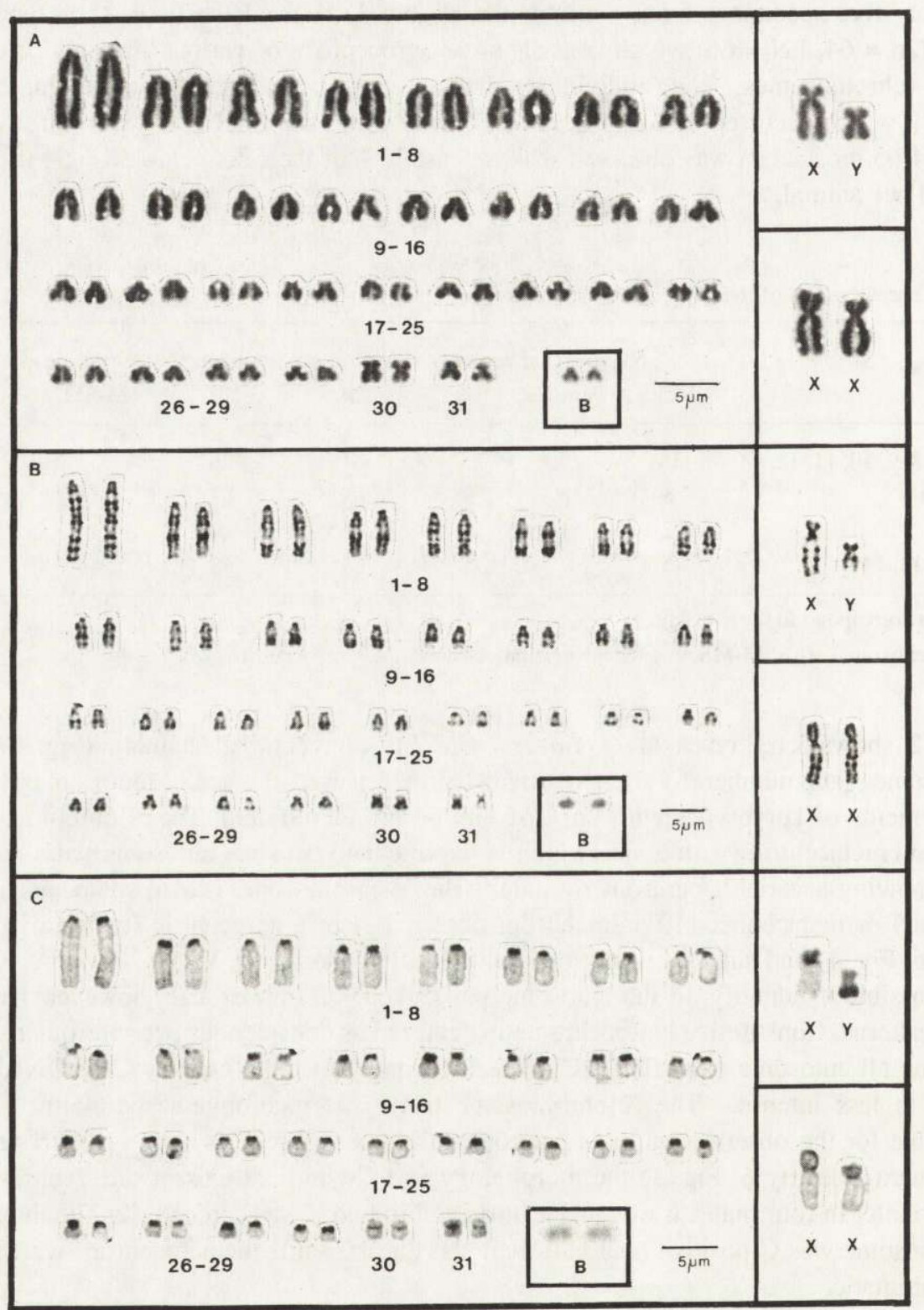

Fig. 2. Karyotypes of O. flavescens. (A) Conventional staining; (B) G-bands; (C) C-bands. The B chromosomes are placed in small rectangles and the sex chromosomes in large rectangles. Note the heteromorphism for the $\mathrm{X}$ chromosome. 

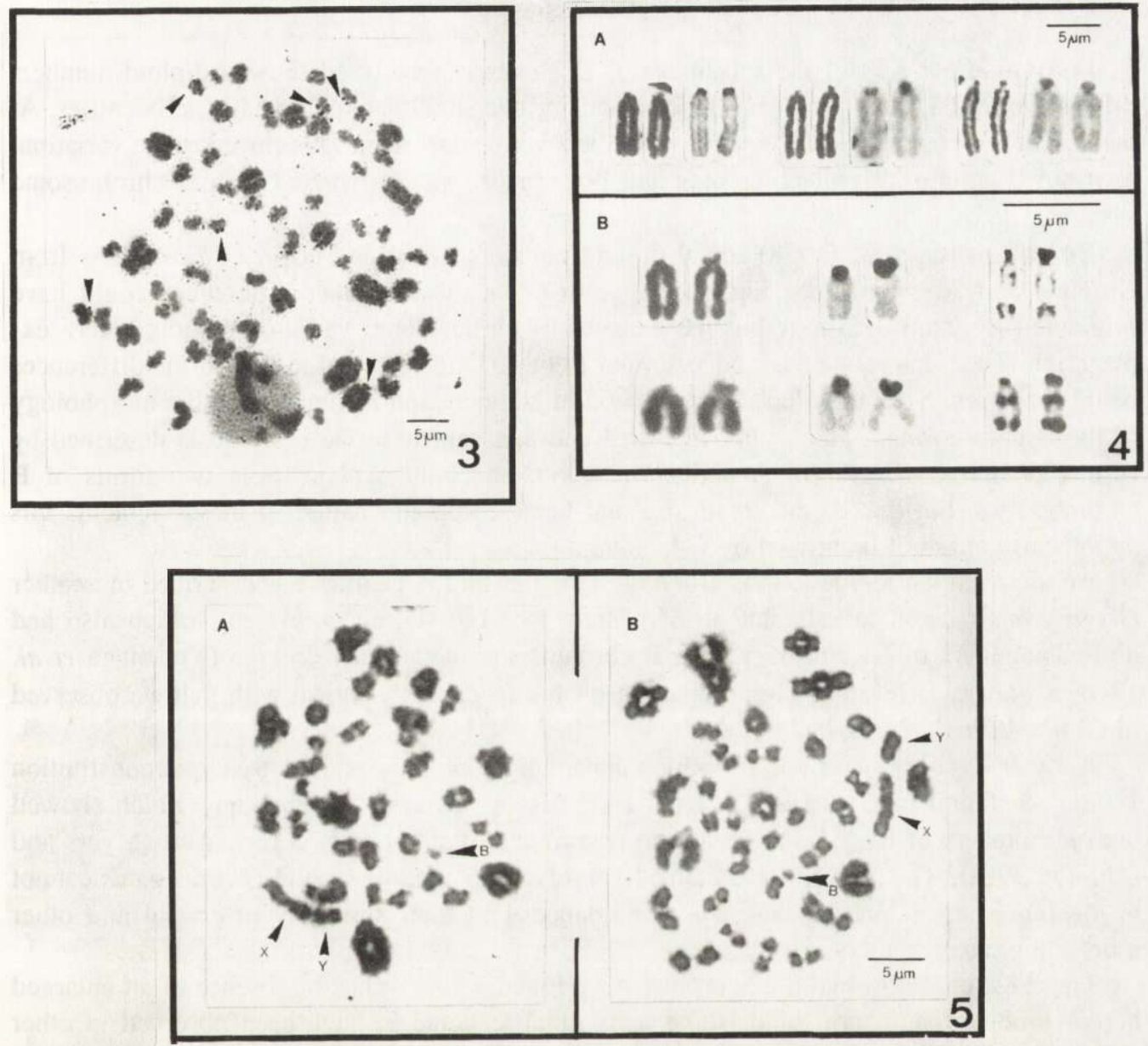

Fïg. 3. Nucleolus organizer regions in $O$. flavescens. Arrows indicate the NOR positions.

Fig. 4. Autosome heteromorphisms. (A) Pair number 1, conventional staining (left) and C-bands (right). (B) Pairs numbers 3 (upper) and 6 (lower), conventional staining and C- and G-bands, respectively.

Fig. 5. Diakinesis-metaphase I plates $(A, B)$ of a $2 n=65$ male. Larger arrows indicate the $B$ univalents and the smaller the end-to-end association of the $\mathrm{X}$ and $\mathrm{Y}$ chromosomes.

heteromorphism was observed on autosome pairs 3 and 6 , in a male from Taim and in a female from Piraquara, respectively (Fig. 4B).

In males with $2 n=64$ and 65 meiosis was analysed. Fig. 5 shows diakinesis-metaphase I cells of a $2 n=65$ male. Thirty-two bivalents plus a B chromosome univalent were observed. The $\mathrm{X}$ and the $\mathrm{Y}$ chromosomes presented end-to-end association, which dissociated precociously eventually (Fig. 5B). 


\section{Discussion}

Forty-nine per cent of the specimens of $O$. flavescens analysed showed diploid numbers different from 64 , due to the occurrence of one or two small heterochromatic acrocentrics. At meiosis of $2 n=65$ males the B chromosome behaved as univalent. This chromosome variation, distributed among all collecting sites and both sexes, was interpreted as a B chromosome system.

Brum-Zorrilla et al. (1988) found diploid numbers of 64 and 66 in O. flavescens from Uruguay and Argentina (see Fig. 1), suggesting that these number differences could have originated by centric fusions but we consider B chromosome variation a more likely explanation. These karyotypes are quite similar to those that we found in Brazil, the differences being the absence of individuals with $2 n=65$ in Uruguay and Argentina and the morphology of the B chromosome: acrocentric in Brazil and metacentric in the individuals described by Brum-Zorrilla et al. (1988). A pericentric inversion could explain these two forms of B chromosomes, but due to the small size and heterochromatic nature of these elements this hypothesis could not be proved by G-banding.

An identical karyotype to those found in Uruguay and Argentina was described in another Olygoryzomys taxon investigated in São Paulo (see Fig. 1), Oryzomys sp., which also had diploid numbers of 64 and 66 with a B chromosome of metacentric type (Yonenaga et al. 1976, Kasahara 1978). The G-band pattern of this species is identical with that we observed in $O$. flavescens.

Another Olygoryzomys species which apparently shares the same karyotypic constitution to that we found in $O$. flavescens from Brazil is $O$. fornesi from Paraguay which showed diploid numbers of 64,65 and 66 due to occurrence of small extra acrocentrics (Myers and Carleton 1981). The conventional stained karyotypes of $O$. fornesi and $O$. flavescens cannot be distinguished, a finding that is in accordance with their similarity in cranial and other morphological characters.

The other chromosomal polymorphisms we found, i.e. presence or absence of an enlarged heterochromatic short arm of outsome pairs number 1 and 3, have been observed in other populations of this species group. The former in Oryzomys sp. from São Paulo (Kasahara 1978) and the latter in O. flavescens from Uruguay and Argentina (Brum-Zorrilla et al. 1988). As far as the morphology of the $\mathrm{Y}$ chromosome is concerned, it was polymorphic (metaacrocentric) in our sample and biarmed in O. flavescens from Uruguay and Argentina, Oryzomys sp. from São Paulo, and $O$. fornesi from Paraguay.

B chromosome variation is quite rare among rodent species. In South America it is known in five cricetid species, two of them being of the Oryzomini tribe: Nectomys squamipes from along the Atlantic coast of Brazil (Maia et al. 1984), and the taxon described here. The similarities in karyotype and pattern of chromosome variation suggest that Oryzomys sp. from São Paulo, O. fornesi, and $O$. flavescens constitute a single cytotaxonomic group with distributional limits in Paraguay, southwestern and south Brazil, Uruguay and Argentina.

Acknowledgements: We thank F. M. Salzano for a critical reading of the manuscript and A. U. Christoff, C. Zotz and C. Borges, for help in the fieldwork. Grants from the Organization of the American States (OAS), Financiadora de Estudos e Projetos (FINEP), and Conselho Nacional de Desenvolvimento Cientifico e Tecnológico (CNPq) are gratefully acknowledged. 


\section{References}

Brum-Zorrilla N., Fronza T. G., Wainberg R., Vidal Rioja L. and Zwirner N. 1988. Oryzomys flavescens and O. delticola chromosomes (Rodentia, Cricetidae) from Uruguay and Argentina. Caryologia 41: 275 - 288.

Carleton M. D. and Musser G. G. 1989. Systematic studies of oryzomyne rodents (Muridae, Sigmodontinae): a sinopsis of Microryzomys. Bull. Am. Mus. Nat. Hist. 191: 1-83.

Ford C. E. and Evans E. P. 1969. Meiotic preparation from mammalian testes. [In: Comparative mammalian cytogenetics. K. Benirschke, ed.]. Springer-Verlag, Berlin, Heidelberg and New York: $461-464$.

Ford C. E. and Hamerton J. L. 1956. A colchicine hypotonic cytrate, squash sequence for mammalian chromosomes. Stain Techn. 31: $247-251$.

Fornes A. and Massoia E. 1965. Small mammals (Marsupialia and Rodentia) collected in the locality of Miramar, Province of Buenos Aires. Physis 25: 98 - 108.

Haiduk M. W., Bickhan J. W. and Schmidly D. J. 1979. Karyotypes of six species of Oryzomys from Mexico and Central America. J. Mamm. 60: 610 - 615.

Howell W. M. and Black D. A. 1980. Controlled silver-staining of nucleolus organizer regions with a protective colloidal developer: a 1-step method. Experientia 36: 1014 - 1015.

Kasahara E. 1978. Variabilidade cromossômica em quatro espécies de roedores das familias Cricetidae a Muridae. Ph. D. Thesis, Universidade de São Paulo, São Paulo: 1 - 163.

Langguth A. 1963. Las especies uruguays del genero Oryzomys (Rodentia-Cricetidae). Com. Zool. Mus. Montevideo 7: $1-23$.

Maia V., Yonenaga-Yassuda Y., Freitas T. R. O., Kasahara S., Suñé-Mattevi M., Oliveira L. F., Galindo M. A. and Sbalqueiro I. J. 1984. Supernumerary chromosomes, Robertsonian rearrangement and variability of the sex chromosomes in Nectomys squamipes (Cricetidae, Rodentia). Genetica 63: 121 - 128.

Myers P. and Carleton M. D. 1981. The species of Oryzomys (Oligoryzomys) in Paraguay and the identity of Azara's "Rat sixime ou Rat Tarse Noir". Misc. Publ. Mus. Univ. Mich. 161: 1 - 41.

Reig O. A. 1986. Diversity patterns and differentiation of high Andean rodents. [In: High altitude tropical biogeography. F. Vuilleumier and M. Monastario, eds]. Oxford University Press, Oxford: 404 - 439.

Seabright M. 1971. A rapid technique for human chromosomes. Lancet 2: 971 - 972.

Sumner A. T. 1972. A simple technique for demonstrating centromeric heterochromatin. Expl. Cell Res. 75: $304-306$.

Yonenaga Y., Frota-Pessoa O., Kasahara S. and Almeida E. J. C. 1976. Cytogenetic studies on Brazilian rodents. Ciên. Cult. 28: $202-211$.

Received 15 February 1991, accepted 16 July 1991. 